\title{
Research
}

\section{Sunrise to Sunset Optimization of Thin Film Antireflective Coatings for Encapsulated, Planar Silicon Solar Cells}

\author{
S. A. Boden ${ }^{* \dagger \dagger}$ and D. M. Bagnall \\ Nano Group, Electronics and Computer Science, University of Southampton, Highfield, Southampton SO17 IBJ, UK
}

We present an approach for the optimization of thin film antireflective coatings for encapsulated planar silicon solar cells in which the variations in the incident spectra and angle of incidence (AOI) over a typical day are fully considered. Both the angular and wavelength dependences of the reflectance from the surface, absorptance within the coating, and transmittance into the device are calculated for both single-and doublelayer antireflection coatings with and without thin silicon oxide passivation layers. These data are then combined with spectral data as a function of time of day and internal quantum efficiency to estimate the average short-circuit current produced by a fixed solar cell during a day. This is then used as a figure of merit for the optimization of antireflective layer thicknesses for modules placed horizontally at the equator and on a roof in the UK. Our results indicate that only modest gains in average short-circuit current could be obtained by optimizing structures for sunrise to sunset irradiance rather than AM1.5 at normal incidence, and fabrication tolerances and uniformities are likely to be more significant. However, we believe that this overall approach to optimization will be of increasing significance for new, potentially asymmetric, antireflection schemes such as those based on subwavelength texturing or other photonic or plasmonic technologies currently under development especially when considered in combination with modules fixed at locations and directions that result in asymmetric spectral conditions. Copyright (C) 2009 John Wiley \& Sons, Ltd.

KEY WORDS: antireflection coating; thin film; SLAR; DLAR; silicon solar cells

Received 22 April 2008; Revised 28 October 2008

\section{INTRODUCTION}

Photovoltaic modules require antireflective schemes in order to gain high efficiency. These schemes include thin film antireflective coatings (ARCs) ${ }^{1-7}$ micronscale texturing in the form of grooves or pyramids, ${ }^{8-9}$

* Correspondence to: S. A. Boden, Nano Group, Electronics and Computer Science, University of Southampton, Highfield, Southampton SO17 1BJ, UK.

†E-mail: sb1@ecs.soton.ac.uk and subwavelength-structured, graded index surfaces. ${ }^{10-15}$ In this paper, we focus only on thin film ARCs for planar solar cells. For this type of AR scheme, materials are chosen with appropriate optical properties and thicknesses to ensure that destructive interference between light reflected from the interfaces in the thin film structure minimizes reflectance and increases the light transmitted into the underlying cell. The destructive interference in the coating and therefore the power conversion of the solar cell is 
dependent on the wavelength and incident angle of light.

A fixed (i.e. non-tracking) solar cell receives light of a wide range of wavelengths incident over a broad range of angles throughout a day. However, device manufacturers have traditionally characterized the performance of devices at normal incidence and for standard irradiances (i.e. AM1.5). As a consequence, most AR schemes have been optimized for conditions that prevail for fixed systems for only a small part of the day. ${ }^{1-4,6}$ Here, we present a method for the assessment of antireflection schemes that takes into account the full range of wavelengths and angles of incidence experienced by a fixed solar cell from sunrise to sunset and apply this method to both singleand double-layer ARCs (SLARs and DLARs).

The transmittance of a surface is combined with solar spectra as a function of time of day and internal quantum efficiency (IQE) data. This leads to a prediction of the full day average short-circuit current which is then used as a figure of merit with which to optimize the design of both single- and double-layer antireflection coatings for a cell encapsulated in an EVA and glass module structure. The optimized ARC thicknesses are compared to those optimized by considering only the AM1.5 spectrum at normal incidence. Finally, as an example of a real world application of the technique, an optimization is carried out with spectral data for a module positioned on a south-facing sloped roof in Southampton, UK.

\section{NUMERICAL METHODS}

We have employed the transfer matrix method of Abeles ${ }^{16}$ to determine the reflectance, and transmittance of a thin film multilayer as this method readily lends itself to analysis for ranges of wavelength, angles of incidence, substrate and thin film refractive indices $(n)$ and extinction coefficients $(k)$, numbers of layers, and layer thicknesses. ${ }^{17}$ The complex refractive index of the layer materials and substrate is used to account for absorption within the layers and to provide accurate values for reflectance at the layer-substrate interface. The resulting transmittance, $T$, is that of the light passing through into the device active area. We can assume that sunlight is, on average, randomly polarized, and this can be simulated by calculating the averages of the results from TE and TM polarizations.

Data for $n$ and $k$ of silicon over a range of wavelengths was obtained from Green. ${ }^{18}$ For $\mathrm{SiO}_{2}$, the
Conrady dispersion formula for refractive index ${ }^{19}$ was used, where $n$ is given by

$$
n(\lambda)=N+\frac{B}{\lambda}+\frac{C}{\lambda^{3.5}}
$$

and

$$
N=1.447, B=0.00374, C=0.00057
$$

The complex refractive index data for the range of wavelengths of interest for $\mathrm{MgF}_{2}, \mathrm{TiO}_{x}, \mathrm{ZnS}$, and five compositions of $\mathrm{SiN}_{x}$ were obtained from Nagel et al. ${ }^{5}$. The five $\mathrm{SiN}_{x}$ films, deposited by remote plasmaenhanced chemical vapor deposition (RPECVD) have decreasing N:Si ratios, and correspondingly increasing $n$ and $k$ values from film \#1 to \#5. Refractive index data for the encapsulation materials EVA and B270 Crown Glass were also obtained from Nagel et al. ${ }^{5}$. Data for $\mathrm{CeO}_{2}$ deposited by a sol-gel spin coating process were obtained from Özer. ${ }^{20}$ Two other commonly used coating materials were considered in this study: $\mathrm{Si}_{3} \mathrm{~N}_{4}$ deposited by low-pressure chemical vapor deposition (LPCVD), which is the ARC material used by BP Solar for their buried contact cell, ${ }^{21}$ and $\mathrm{TiO}_{2}$ deposited by spray pyrolysis, which was used extensively for screen-printed solar cells ${ }^{22,23}$ but has now largely been superseded by PECVD $\mathrm{SiN}_{x}$. LPCVD $\mathrm{Si}_{3} \mathrm{~N}_{4}$ refractive index data were obtained from Djurisic and $\mathrm{Li}^{24}$ and $\mathrm{TiO}_{2}$ data were obtained from Richards. ${ }^{23}$

It is important to note that the optical properties of thin film materials vary considerably with deposition method and conditions. For instance, Richards ${ }^{25}$ showed that the refractive index of $\mathrm{TiO}_{2}$ films can be varied by altering the density and phase of the material through different deposition conditions and post-deposition sintering. Likewise, Khawaja et al. ${ }^{26}$ report that differences in the columnar microstructure of some $\mathrm{CeO}_{2}$ films lead to variations in optical properties between films deposited by evaporation under different conditions and even inhomogeneity in refractive index along the depth of a single film. Therefore, each film studied here should be considered as a specific example and not necessarily as representative of the material as a whole.

\section{Spectral Data}

Solar spectrum data provided by SPCTRAL2 from National Renewable Energy Laboratory (NREL) were used. ${ }^{27}$ This program allows longitude, latitude, and slope to be specified along with a date and time (other inputs are listed in Table I). The direct and diffuse 
Table I. Input parameters used in SPCTRL2 $\operatorname{program}^{27}$

\begin{tabular}{lcc}
\hline & $\begin{array}{c}\text { Equator } \\
\text { cell }\end{array}$ & $\begin{array}{c}\text { Southampton } \\
\text { cell }\end{array}$ \\
\hline Latitude $\left(^{\circ}\right)$ & 0 & 50.93 \\
Longitude $\left(^{\circ}\right)$ & 0 & $-1 \cdot 40$ \\
Aerosol optical depth & $0 \cdot 27$ & $0 \cdot 27$ \\
Alpha & $1 \cdot 14$ & $1 \cdot 14$ \\
Albedo (surface reflectance) & $0 \cdot 2$ & $0 \cdot 2$ \\
Total column ozone $(\mathrm{cm})$ & $0 \cdot 34$ & $0 \cdot 34$ \\
Total precipitable water vapor $(\mathrm{cm})$ & $1 \cdot 42$ & $1 \cdot 42$ \\
Slope $\left({ }^{\circ}\right)$ & 0 & $22 \cdot 6$ \\
Surface pressure $(\mathrm{mB})$ & $1013 \cdot 25$ & $1013 \cdot 25$ \\
Day of the year & 79 (Mar 20) & 79 (Mar 20) \\
\hline
\end{tabular}

The equator cell is simulated on a horizontal surface. The Southampton cell is simulated as mounted on a rooftop with a 5/12 slope.

irradiances (in units of $\mathrm{W} / \mathrm{m}^{2} /$ micron interval) are then calculated for a range of wavelengths for times in 5-min intervals. In this analysis, data are compiled from 6:08 am, which corresponds to an angle of incidence (AOI) for direct light of $90^{\circ}$ (sun at the horizon, dawn), until 12:08 am, corresponding to an AOI of $0^{\circ}$ (sun directly overhead, noon).

An array of direct irradiances for a range of wavelengths and AOIs representing the direct solar radiation experienced by a horizontally fixed solar cell at the equator is compiled. These data are then multiplied by the cosine of the incident angle to account for the increase in projected area with AOI and then integrated over the wavelength intervals using the trapezoid method to obtain irradiance in units of $\mathrm{W} / \mathrm{m}^{2}$.

Diffuse light is light scattered from the ground and from particles in the atmosphere. SPCTRAL2 provides diffuse spectral data for time of day, but this does not correspond to particular AOIs. We can assume that diffuse radiation is incident over all angles equally throughout the day. Again, we integrate this using the trapezoid method to obtain irradiance in $\mathrm{W} / \mathrm{m}^{2}$, sum the data for each wavelength and divide by the number of time intervals to calculate an average value of diffuse irradiance for each wavelength.

The integrated diffuse and cosine-corrected direct spectra are summed to obtain the total irradiance, $I_{\mathrm{T}}$, incident on a cell over half a day, as a function of wavelength and AOI. The total photon flux density, PFD (photons $/ \mathrm{m}^{2} / \mathrm{s}$ ) (see Figure 1), is then given by dividing by the energies of the photons, that is,

$$
\operatorname{PFD}(\lambda, \theta)=\frac{I_{T}(\lambda \theta) \lambda}{h c}
$$

where $h$ is Planck's constant and $c$ is the speed of light.

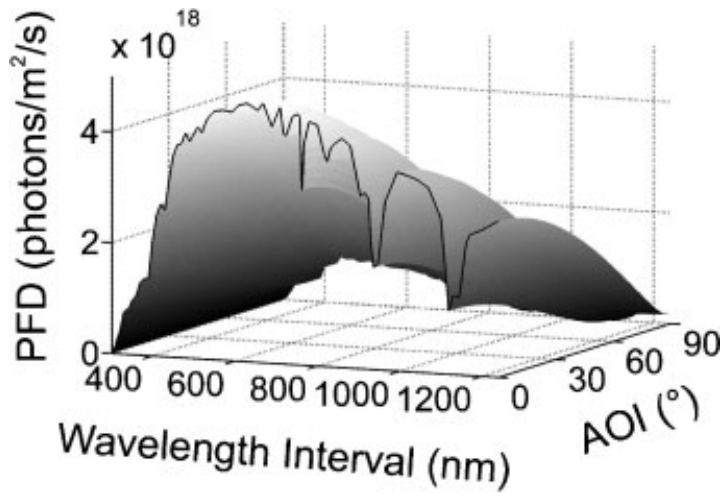

Figure 1. Total PFD spectra compiled from SPCTRAL2 27

\section{Encapsulation}

When employed for power generation, solar cells are encapsulated in EVA and glass to provide protection from moisture that would quickly corrode the contacts and adversely affect the performance of the cell. The optimum thicknesses and refractive indices for encapsulated cell ARCs will be substantially different to those of a laboratory cell because of the change in the refractive index of the superstrate material due to consideration of an EVA-silicon interface rather than an air-silicon interface. Also, the wavelength and angular characteristics of the incident spectrum of light will be altered by transmission through the encapsulant materials. To account for this, reflectance at a planar glass surface, $R_{\text {glass }}$, is calculated. The new propagation angle of light, $\varphi$, due to refraction at the airglass interface is given by Snell's law. The path length, $p$, of light traveling through an EVA layer of thickness $t$ is then given by:

$$
p=\frac{t}{\cos \varphi}
$$

This is combined with the extinction coefficient of EVA, $k_{\mathrm{EVA}}$, to calculate transmission, $T_{\mathrm{EVA}}$, through a standard $0.45 \mathrm{~mm}$ thick ${ }^{28}$ layer of EVA encapsulation using

$$
T_{\mathrm{EVA}}(\lambda, \varphi)=\exp \left(\frac{-4 \pi k_{\mathrm{EVA}}(\lambda)}{\lambda} p(\varphi)\right)
$$

The PFD incident over half a day on a cell beneath encapsulation ( $\mathrm{PFD}_{\text {encap }}$ ), as a function of wavelength and AOI, is then given by

$$
P F D_{\text {encap }}(\lambda, \varphi)=\operatorname{PFD}(\lambda, \varphi)\left(1-R_{\text {glass }}(\lambda, \varphi)\right) T_{\mathrm{EVA}}(\lambda, \varphi)
$$



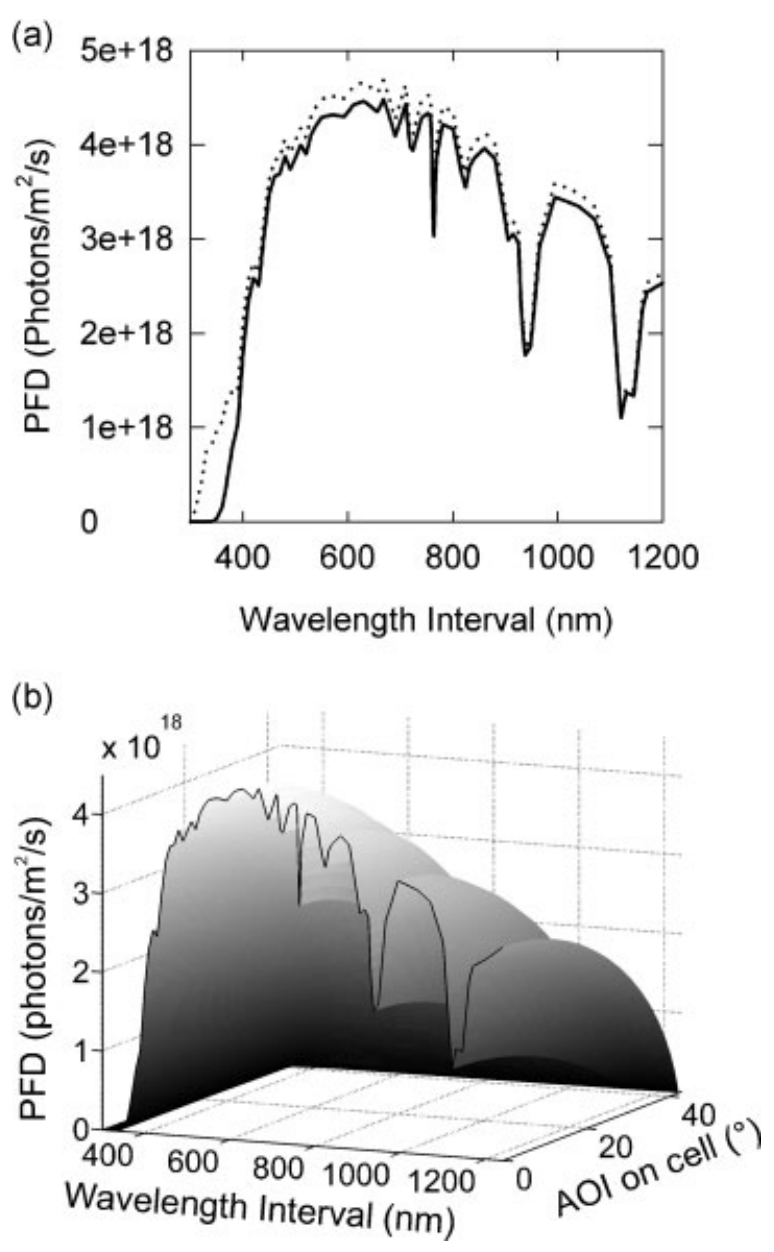

Figure 2. Total PFD spectra for an encapsulated solar cell, where AOI is that at the EVA-cell interface. The wavelength interval is $1 \mathrm{~nm}$. (a) Normal incidence spectrum (solid line) with spectrum on module surface (dotted line) for comparison. (b) Angular spectral distribution for half a day

A comparison of PFD incident on the module surface with PFD incident on the cell underneath encapsulation at normal incidence is shown in Figure 2a. A surface plot of $P F D_{\text {encap }}(\lambda, \theta)$ is presented in Figure 2. Differences between this and the PFD on the module surface include an overall decrease in PFD due to reflectance at the air-glass interface; low values in the UV range due to absorption by EVA; a smaller angular range due to refraction at the air-glass interface and the number of photons falling to zero at the largest angle because this corresponds to light incident on the glass cover at close to $90^{\circ}$, at which reflectance from the glass cover is near to $100 \%$.
The analysis assumes that there is no absorption in the glass layer, which is justified by the negligible values of $k$ for this material given by Nagel et al. ${ }^{5}$ Reflection at the glass-EVA interface is also considered to be negligible because of the closely matched refractive indices of these two materials. The model also does not account for multiple passes of light through the glassEVA structure; however, after the first reflection at the EVA-silicon interface, any returning light will be at least two orders of magnitude less intense.

\section{$I Q E$}

An IQE curve for a typical screen-printed monocrystalline solar cell is obtained from Ebong et al. ${ }^{29}$. However, this includes absorption in the thin film ARC, which is a layer of PECVD $\operatorname{SiN}_{x}$ with a thickness, $t$, of $86 \mathrm{~nm}$. To avoid counting ARC absorption twice, the effect of this absorption is removed from the IQE data using

$$
\operatorname{IQE}(\lambda)=I Q E_{0}(\lambda) \exp \frac{4 \pi k_{\mathrm{SiN}_{x}}(\lambda)}{\lambda} t
$$

Where $\mathrm{IQE}_{0}$ is the original IQE data, and $k_{\mathrm{SiN} x}$ is the extinction coefficient for the thin film ARC. Extinction coefficient data for the actual film used are not available, and so $k$ values for the RPECVD $\mathrm{SiN}_{x} \# 2$ film from Nagel et al. ${ }^{5}$ are used. The original and ARC absorption-corrected IQE curves are presented in Figure 3.

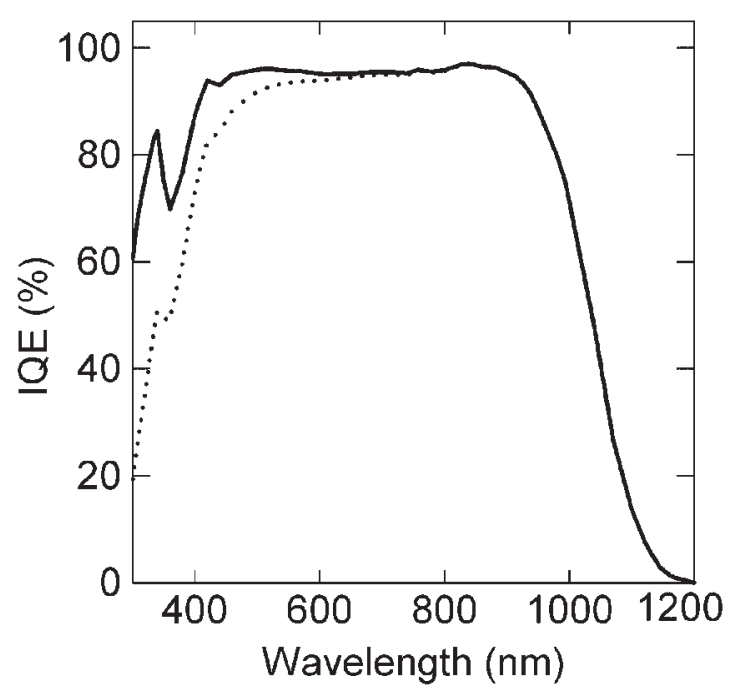

Figure 3. IQE data for screen-printed cell modeled in this study (from Ebong et al. ${ }^{29}$ ). Dotted line: original IQE data, solid line: IQE data with effect of absorption in thin film ARC removed 
A short-circuit current density, $J_{\mathrm{sc}}\left(\mathrm{A} / \mathrm{m}^{2}\right)$, for each time interval between dawn and noon is then calculated by combining the total PFD, the transmittance, $T$, and the IQE, for each time of day from dawn until noon.

$$
J_{\mathrm{sc}}(\theta)=q \int_{\lambda=300 \mathrm{~nm}}^{\lambda=1240 \mathrm{~nm}}[\operatorname{PFD}(\lambda, \theta) T(\lambda, \theta) \operatorname{IQE}(\lambda)]
$$

Summing over all time intervals, multiplying this by the number of seconds per time interval and dividing by the number of seconds in half a day gives us an average short-circuit current $J_{\text {scAve. }}$. A simplex-based search method ${ }^{30}$ is used to optimize the thin film layer parameters, using $J_{\text {scAve }}$ as the figure of merit to maximize.

\section{ENCAPSULATED CELL RESULTS}

\section{Single-layer ARCs (SLARs)}

Optimizing for both refractive index and thickness results in values of 2.42 and $63.6 \mathrm{~nm}$, respectively, which indicates that the higher refractive index materials will be more effective for $A R$ in the encapsulated cell case. This is found to be true as the results in Table II demonstrate, with the higher refractive index materials such as $\mathrm{TiO}_{2}, \mathrm{TiO}_{x}$, and $\mathrm{ZnS}$ predicted to be the most effective. The best-performing SLAR is that of $\mathrm{TiO}_{2}$, with a thickness of $62.5 \mathrm{~nm}$. This represents a loss of only $4.6 \%$ when compared with an ideal ARC (i.e. $100 \%$ transmission through the EVAsilicon interface for all angles and wavelengths). Plots of $J_{\text {scAve }}$ versus layer thickness (Fig. 4) confirm that global maxima were found in the optimizations.
$\mathrm{Si}_{3} \mathrm{~N}_{4}$ is considered to be non-absorbing across the entire wavelength range of interest. Extinction coefficient data were available for $\mathrm{Si}_{3} \mathrm{~N}_{4}$, which showed this was indeed the case. ${ }^{24}$ The poor performances of $\mathrm{CeO}_{2}$ and the silicon-rich RPECVD $\mathrm{SiN}_{x}$ examples are due to a combination of nonoptimal refractive index ranges and high levels of absorption. Reasonable levels of UV absorption, as exhibited by some of the best-performing films (e.g. $\mathrm{TiO}_{2}, \mathrm{TiO}_{x}$, and $\mathrm{ZnS}$ ), are not necessarily detrimental for solar cell applications because the solar irradiance is low in this region. However, the worse-performing films absorb at wavelengths beyond this, causing films of $\mathrm{CeO}_{2}, \mathrm{SiN}_{x} \# 3, \mathrm{SiN}_{x} \# 4$, and $\mathrm{SiN}_{x} \# 5$ to cease to confer an AR effect for thicknesses above 137, 165, 113 , and $86 \mathrm{~nm}$, respectively (see Figure 4).

\section{Surface passivation considerations}

Silicon dioxide is of no use as an ARC for encapsulated cells because its refractive index is too close to that of the EVA medium. However, it is often used as a thin layer between the ARC and silicon to provide surface passivation. For the high IQE shown in Figure 3 to be achieved in a real solar cell, the surfaces of the cell have to be passivated to inhibit losses due to surface recombination. Thermally grown silicon oxide provides excellent passivation for most silicon solar cell surfaces (the exception being for low-resistivity $p$-type wafers). With its excellent passivation properties due to both a reduction in surface states or 'dangling ' bonds and a field passivation effect due to positive charges within the oxide repelling holes from the surface, it is

Table II. Optimized parameters for SLARs at an EVA-silicon interface in an encapsulated solar cell $\left(d_{\text {opt }}\right.$ is the optimized layer thickness)

\begin{tabular}{|c|c|c|c|}
\hline SLAR for encapsulated cell & Opt. $d(\mathrm{~nm})$ & $J_{\text {scAve }}\left(\mathrm{mA} / \mathrm{cm}^{2}\right)$ & $\%$ loss \\
\hline Ideal ARC & - & $22 \cdot 36$ & 0 \\
\hline $\mathrm{TiO}_{2}$ & $62 \cdot 49$ & $21 \cdot 34$ & $4 \cdot 6$ \\
\hline $\mathrm{ZnS}$ & $65 \cdot 08$ & $21 \cdot 25$ & $5 \cdot 0$ \\
\hline $\mathrm{TiO}_{x}$ & $66 \cdot 68$ & $21 \cdot 17$ & $5 \cdot 3$ \\
\hline LPCVD $\mathrm{Si}_{3} \mathrm{~N}_{4}$ & $77 \cdot 45$ & $20 \cdot 76$ & $7 \cdot 1$ \\
\hline $\operatorname{RPECVD~SiN}_{x} \# 2$ & $75 \cdot 56$ & $20 \cdot 47$ & 8.4 \\
\hline $\operatorname{RPECVD~SiN}_{x} \# 3$ & $67 \cdot 92$ & $20 \cdot 34$ & $9 \cdot 0$ \\
\hline 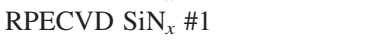 & $84 \cdot 64$ & $20 \cdot 06$ & $10 \cdot 3$ \\
\hline $\operatorname{RPECVD~SiN}_{x} \# 4$ & $59 \cdot 11$ & $19 \cdot 58$ & $12 \cdot 4$ \\
\hline $\operatorname{RPECVD~SiN}_{x} \# 5$ & $51 \cdot 30$ & $18 \cdot 92$ & $15 \cdot 4$ \\
\hline $\mathrm{CeO}_{2}$ & $74 \cdot 25$ & $18 \cdot 87$ & $15 \cdot 6$ \\
\hline Bare Si with $2 \mathrm{~nm}$ native oxide & - & $18 \cdot 00$ & $19 \cdot 5$ \\
\hline
\end{tabular}

$J_{\text {scAve }}$ is the predicted average short-circuit current produced in a coated cell over a whole day. "\% loss" is the percentage reduction in $J_{\text {scAve }}$ if replacing an ideal ARC (i.e. 100\% transmission for all angles and wavelengths). 
(a)

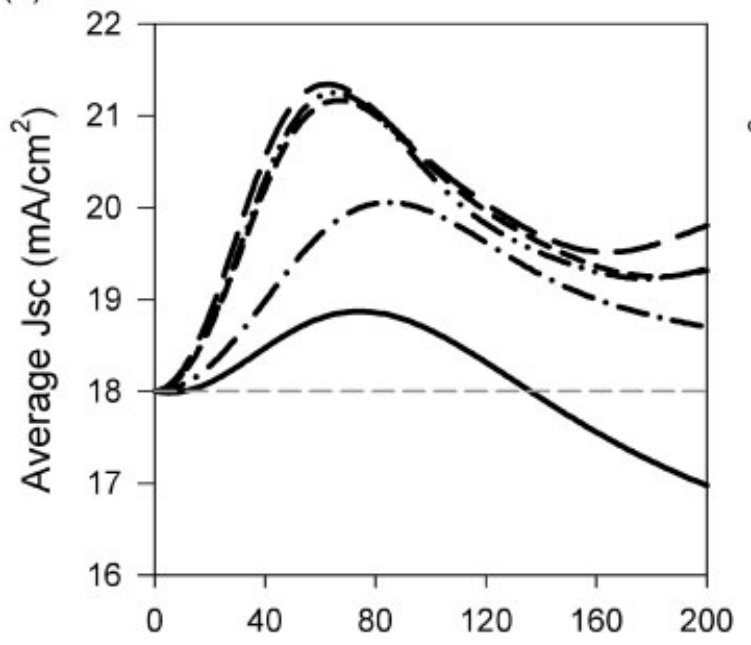

Layer thickness $(\mathrm{nm})$

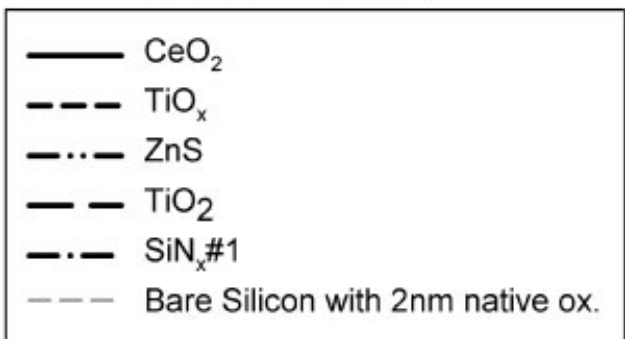

(b)
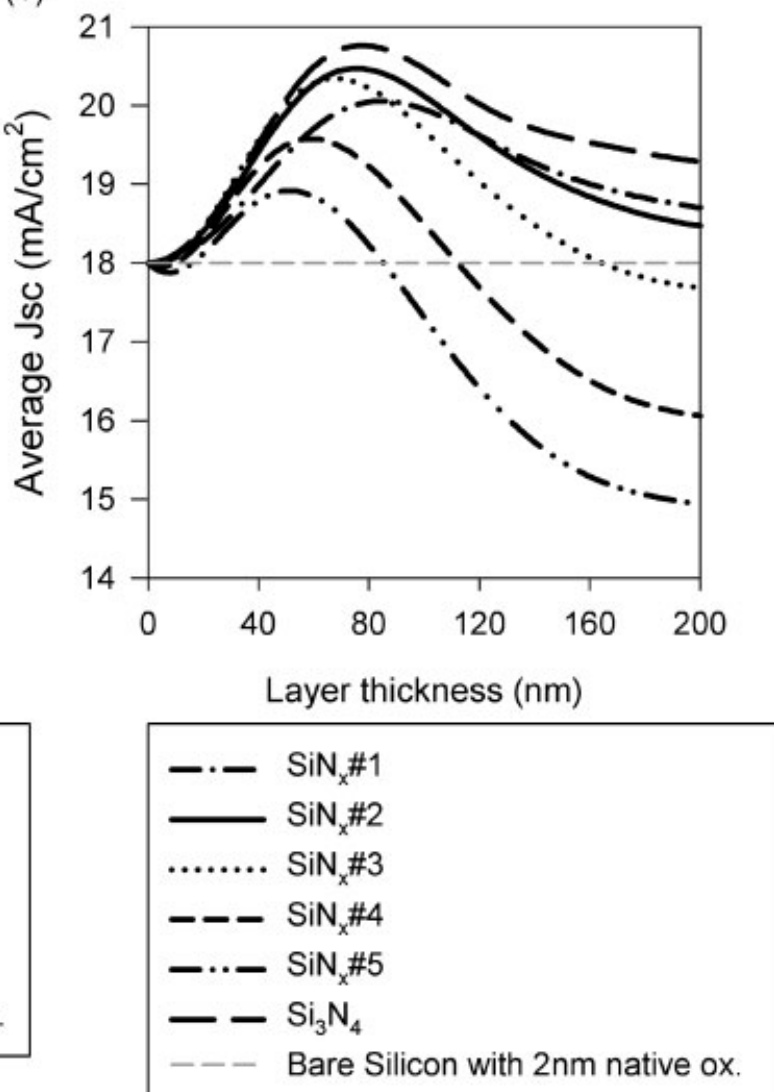

Figure 4. Predictions of the variation, with coating thickness, of the average short-circuit current produced by an encapsulated cell over a whole day with various single-layer ARCs: (a) non nitride coatings (with $\mathrm{SiN}_{\mathrm{x}} \# 1$ included for comparison); (b) nitride coatings

the most commonly used coating for high efficiency lab cells. ${ }^{31}$ Surface recombination velocities of less than $10 \mathrm{~cm} / \mathrm{s}$ have been reported for a silicon surface passivated with a thermally grown oxide. ${ }^{32}$ Our analysis shows that thin films of $\mathrm{TiO}_{2}, \mathrm{TiO}_{x}$, and $\mathrm{ZnS}$ are good AR coatings, but unfortunately, these films provide negligible electrical passivation to the silicon surface. ${ }^{5,33,7}$ PECVD silicon nitride films can be very effective for surface passivation, with record low values of surface recombination velocity of $4 \mathrm{~cm} / \mathrm{s}$ being reported. ${ }^{34}$ Alas, the best passivating nitride films are those with a high silicon content, closer to the $\mathrm{SiN}_{x} \# 5$ film, which we have discovered is too absorbing to be an effective AR coating. There are some reports of good passivation with silicon-poor $\mathrm{SiN}_{x}$ films, ${ }^{35}$ but the authors concede that the film suffers from a poor thermal stability and that the conditions required to grow the film are difficult to optimize.
To improve the surface passivation of the thin film layers, a thin layer of $\mathrm{SiO}_{2}$ is often thermally grown onto the substrate before the application of the other ARC material. Nagel et al. ${ }^{5}$ suggest a $20 \mathrm{~nm}$ thick oxide layer whereas other groups report that a 10 or even $5 \mathrm{~nm}$ layer thickness is sufficient in some cases to achieve effective surface passivation. ${ }^{1,33,35}$ For certain cells such as the University of New South Wales passivated emitter and rear cells (PERCs), an oxide thickness greater than $30 \mathrm{~nm}$ is required. ${ }^{36}$ The variation in $J_{\text {scAve }}$ with thickness of a passivating oxide included in the SLARs is shown in Figure 5. The thickness of the top layer was re-optimized for each oxide thickness tested (Fig. 5b). Values of the percentage drop in $J_{\text {scAve }}$ for a $20 \mathrm{~nm}$ oxide, given by

$$
\% \text { drop in } J_{\text {scAve }}=\frac{\left.J_{\mathrm{scAve}}\right|_{0 \mathrm{~nm}}-\left.J_{\mathrm{scAve}}\right|_{20 \mathrm{~mm}}}{\left.J_{\mathrm{scAve}}\right|_{0 \mathrm{~mm}}} \times 100
$$

are shown in Table III. 
(a)

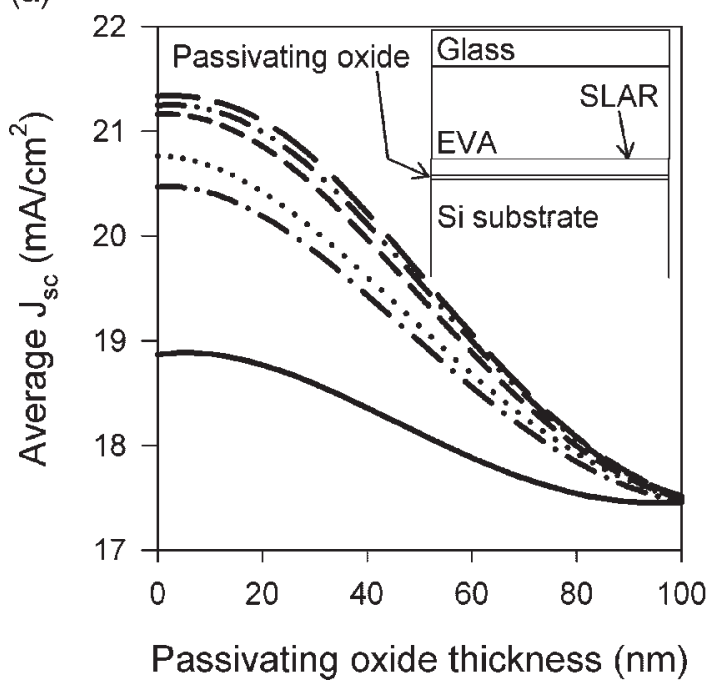

(b)

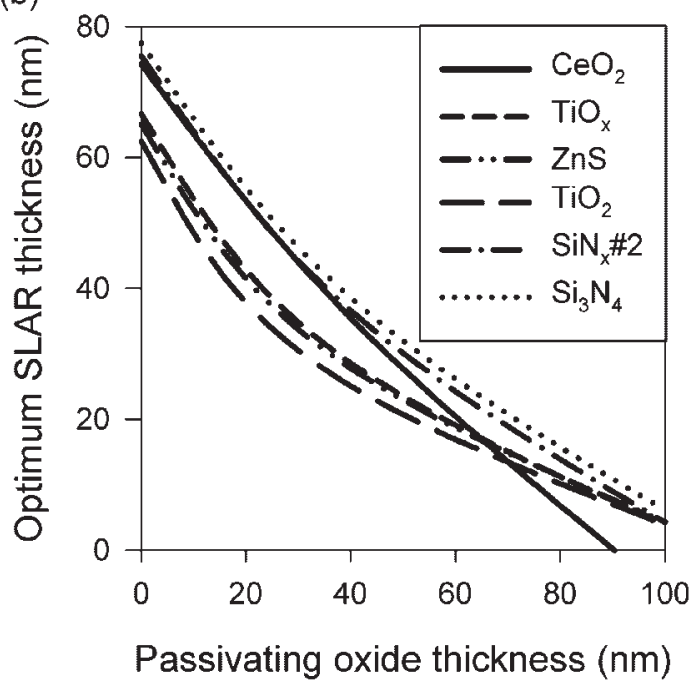

Figure 5. The effect of including a passivating oxide between a SLAR and the silicon substrate in an encapsulated cell: (a) predicted average short-circuit current produced by an SLAR coated cell over a day as a function of passivating oxide thickness; (b) optimum SLAR thickness variation with passivating oxide thickness

Table III. The predicted percentage drop in average short-circuit current produced by an encapsulated solar cell over a whole day with an optimized SLAR when a $20 \mathrm{~nm}$ passivating oxide is added

\begin{tabular}{|c|c|c|c|c|c|}
\hline SLAR & $\begin{array}{c}\text { Opt. } d \text { no } \\
\text { passivation }(\mathrm{nm})\end{array}$ & $\begin{array}{c}\text { Opt. } d \text { with } \\
\text { passivation }(\mathrm{nm})\end{array}$ & $\begin{array}{c}J_{\text {scAve }} \text { no } \\
\text { passivation }\left(\mathrm{mA} / \mathrm{cm}^{2}\right)\end{array}$ & $\begin{array}{c}J_{\text {scAve }} \text { with } \\
\text { passivation }\left(\mathrm{mA} / \mathrm{cm}^{2}\right)\end{array}$ & $\begin{array}{l}\% \text { drop in } J_{\text {scave }} \\
\text { with } 20 \mathrm{~nm} \\
\text { passivating oxide }\end{array}$ \\
\hline $\mathrm{TiO}_{2}$ & 62.49 & 37.81 & $21 \cdot 34$ & $21 \cdot 10$ & $1 \cdot 13$ \\
\hline $\mathrm{ZnS}$ & $65 \cdot 08$ & $41 \cdot 48$ & $21 \cdot 25$ & 20.99 & $1 \cdot 20$ \\
\hline $\mathrm{TiO}_{x}$ & $66 \cdot 68$ & $42 \cdot 88$ & $21 \cdot 17$ & $20 \cdot 86$ & 1.47 \\
\hline $\mathrm{Si}_{3} \mathrm{~N}_{4}$ & 77.45 & $55 \cdot 38$ & $20 \cdot 76$ & $20 \cdot 42$ & 1.64 \\
\hline $\mathrm{SiN}_{x} \# 2$ & $75 \cdot 56$ & $53 \cdot 35$ & $20 \cdot 47$ & $20 \cdot 19$ & $1 \cdot 37$ \\
\hline $\mathrm{CeO}_{2}$ & 74.25 & $53 \cdot 38$ & $18 \cdot 87$ & $18 \cdot 77$ & 0.53 \\
\hline
\end{tabular}

The results show that all coatings are adversely affected by the inclusion of an oxide. Drops in $J_{\text {scAve }}$ of between 0.5 and $1.6 \%$ are predicted when a $20 \mathrm{~nm}$ thick oxide layer is included.

\section{Double-layer ARCs (DLARs)}

Double-layer antireflection coatings (DLARs) can be designed to provide a broader-band AR effect than SLARs. With two layers, more parameters are available for optimization, and destructive interference is optimized for more than one central wavelength.

The results of the optimizations of encapsulated DLARs made with the material combinations that exhibited an AR effect are shown in Figure 6, with the parameters of the best-performing DLARs shown in Table IV. This analysis reveals that only three combinations of the materials investigated (namely

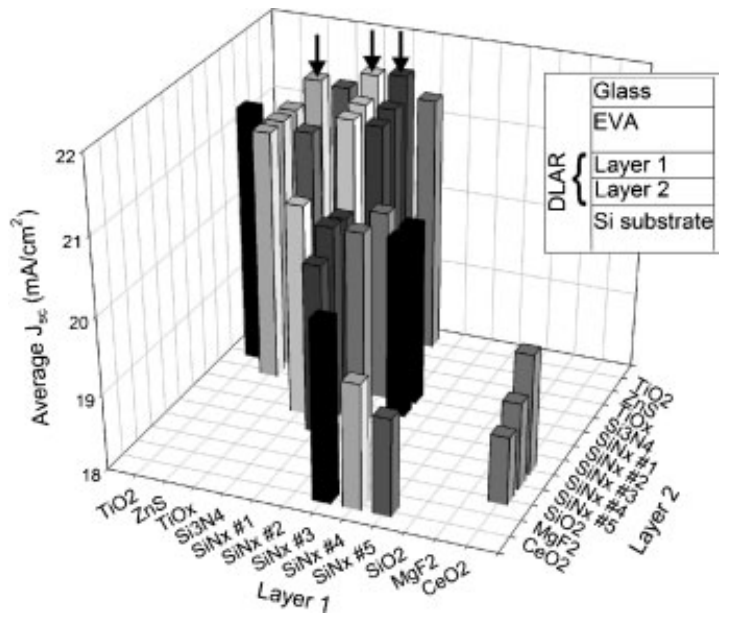

Figure 6. Results for optimization of DLARs of various materials on an encapsulated cell. Arrows indicate coatings with AR performances exceeding that of the optimized $\mathrm{TiO}_{2}$ SLAR. 
Table IV. Optimum parameters for DLARs in an encapsulated cell

\begin{tabular}{lcccr}
\hline $\begin{array}{l}\text { DLAR } \\
(\mathrm{L} 1 / \mathrm{L} 2)\end{array}$ & $\begin{array}{c}\text { Opt. } \\
d_{1}(\mathrm{~nm})\end{array}$ & $\begin{array}{c}\text { Opt. } \\
d_{2}(\mathrm{~nm})\end{array}$ & $\begin{array}{l}J_{\text {scAve }} \\
\left(\mathrm{A} / \mathrm{m}^{2}\right)\end{array}$ & $\begin{array}{c}\% \\
\text { loss }\end{array}$ \\
\hline $\mathrm{Ideal}$ & - & - & $22 \cdot 36$ & 0 \\
$\mathrm{SiN}_{x} \# 1 / \mathrm{TiO}_{2}$ & $66 \cdot 11$ & $56 \cdot 13$ & 21.59 & 3.45 \\
$\mathrm{Si}_{3} \mathrm{~N}_{4} / \mathrm{TiO}_{2}$ & $51 \cdot 34$ & $48 \cdot 61$ & 21.55 & 3.64 \\
$\mathrm{ZnS}_{\mathrm{TiO}}$ & 27.85 & $38 \cdot 83$ & 21.37 & 4.42 \\
\hline
\end{tabular}

Layer 1 is the top layer, next to air. $J_{\text {scAve }}$ is the predicted average short-circuit current produced in a coated cell over a whole day. " $\%$ loss" is the percentage reduction in $J_{\text {scAve }}$ if replacing an ideal ARC (i.e. 100\% transmission for all angles and wavelengths). Only DLARs with predicted performances greater than the best SLAR are shown.

$\mathrm{SiN}_{x} \# 1 / \mathrm{TiO}_{2}, \mathrm{Si}_{3} \mathrm{~N}_{4} / \mathrm{TiO}_{2}$, and $\mathrm{ZnS} / \mathrm{TiO}_{2}$ ) combine to produce DLARs that outperform the best SLAR $\left(\mathrm{TiO}_{2}\right)$, with the best DLAR in the study $\left(\mathrm{SiN}_{x} \# 1 /\right.$ $\mathrm{TiO}_{2}$ ) exhibiting a $3.5 \%$ loss compared to an ideal AR interface. Parameter scans across the thicknesses of both layers confirm that the optimizations identified the global maxima in $J_{\text {scAve }}$ (see Figure 7). Passivation has also been considered for encapsulated DLARs: The variations in $J_{\text {scAve }}$ and optimum layer thickness with thickness of oxide are plotted in Figure 8. Values for the percentage drop in $J_{\text {scAve }}$ when a $20 \mathrm{~nm}$ thick oxide is added (Table V) show that the performance of the DLARs decreases by between 1.2 and $2.3 \%$. For the $\mathrm{SiN}_{x} \# 1 / \mathrm{TiO}_{2}$ coating, the optimum layer 1
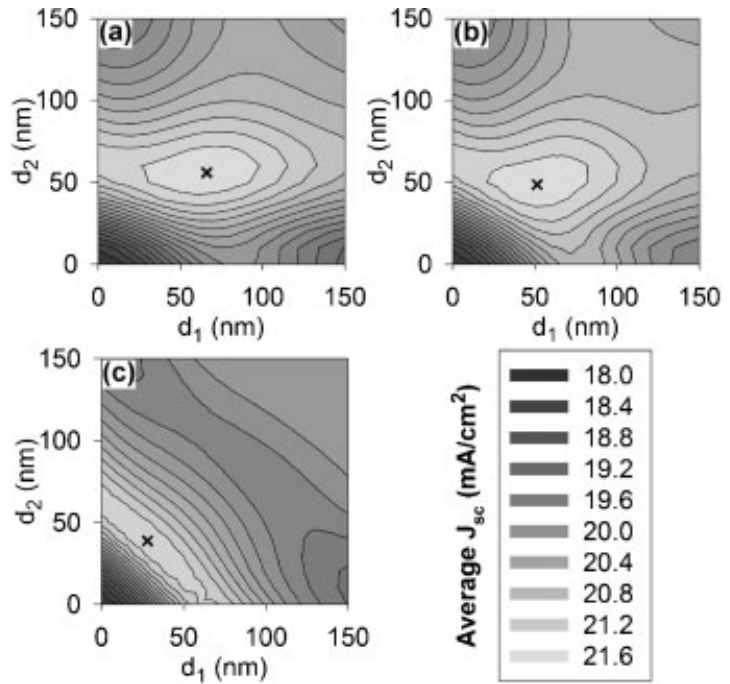

Figure 7. Results for parameter scans across layer thicknesses of best DLARs on an encapsulated cell: (a) $\mathrm{SiN}_{x} \# 1 / \mathrm{TiO}_{2}$, (b) $\mathrm{Si}_{3} \mathrm{~N}_{4} /$ $\mathrm{TiO}_{2}$, and (c) $\mathrm{ZnS} / \mathrm{TiO}_{2}$. Crosses mark the optimum designs (a)

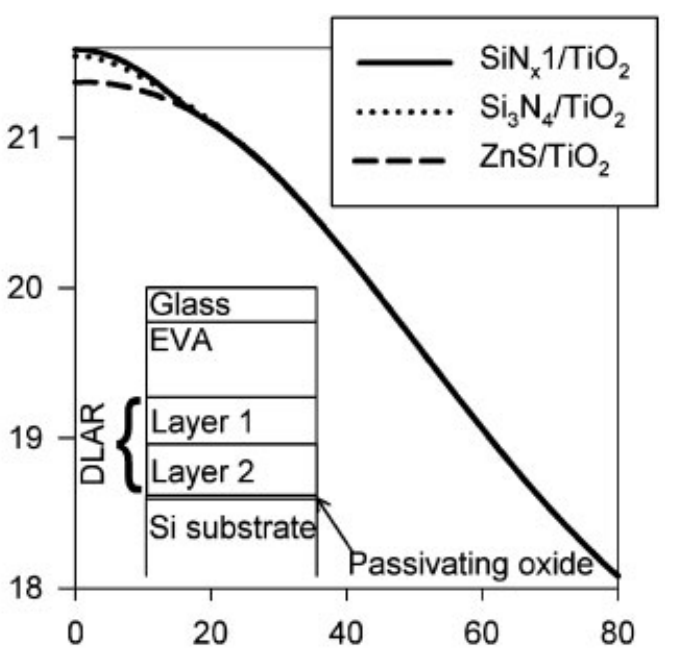

Passivating oxide thickness $(\mathrm{nm})$

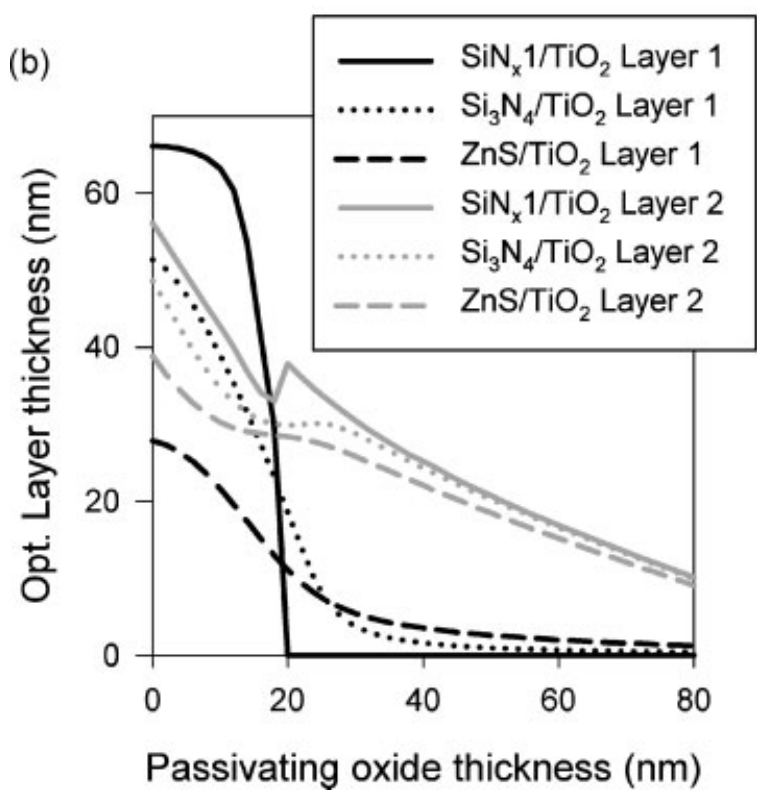

Figure 8. The effect of including a passivating oxide between a DLAR and the silicon substrate in an encapsulated cell: (a) average short-circuit current produced by an DLARcoated cell over a day as a function of passivating oxide thickness; (b) variation of optimum DLAR thicknesses with passivating oxide thickness

thickness drops to zero for oxide thicknesses above $20 \mathrm{~nm}$, indicating that a passivated $\mathrm{TiO}_{2}$ SLAR is most effective. Performances of the other DLARs, once passivated, are also predicted to be similar to that of a passivated $\mathrm{TiO}_{2}$ SLAR, with a percentage loss 
Table V. The percentage drop in average short-circuit current produced by a encapsulated solar cell over a whole day with an optimized DLAR when a $20 \mathrm{~nm}$ passivating oxide is added

\begin{tabular}{|c|c|c|c|c|}
\hline DLAR & L1 & $\operatorname{SiN}_{x} \# 1$ & $\mathrm{Si}_{3} \mathrm{~N}_{4}$ & $\mathrm{ZnS}$ \\
\hline & $\mathrm{L} 2$ & $\mathrm{TiO}_{2}$ & $\mathrm{TiO}_{2}$ & $\mathrm{TiO}_{2}$ \\
\hline \multirow[t]{2}{*}{ Opt. $d(\mathrm{~nm})$ without passivation } & $d_{1}$ & $66 \cdot 11$ & $51 \cdot 34$ & $27 \cdot 85$ \\
\hline & $d_{2}$ & $56 \cdot 13$ & $48 \cdot 61$ & $38 \cdot 83$ \\
\hline \multirow[t]{2}{*}{ Opt. $d(\mathrm{~nm})$ with passivation } & $d_{1}$ & 0 & $18 \cdot 61$ & 11.09 \\
\hline & $d_{2}$ & $37 \cdot 81$ & $29 \cdot 81$ & $28 \cdot 38$ \\
\hline$J_{\mathrm{scAve}}$ without passivation $\left(\mathrm{mA} / \mathrm{cm}^{2}\right)$ & & $21 \cdot 59$ & $21 \cdot 55$ & $21 \cdot 37$ \\
\hline$J_{\text {scAve }}$ with passivation $\left(\mathrm{mA} / \mathrm{cm}^{2}\right)$ & & $21 \cdot 10$ & $21 \cdot 11$ & $21 \cdot 10$ \\
\hline$\%$ drop in $J_{\text {scAve }}$ with passivation & & $2 \cdot 26$ & $2 \cdot 01$ & $1 \cdot 24$ \\
\hline
\end{tabular}

Table VI. Comparison of full sunrise to sunset simulations with AM1·5, normal incidence simulations for the encapsulated cell

\begin{tabular}{|c|c|c|c|c|c|c|c|}
\hline Coating & & $\begin{array}{c}\mathrm{SiN}_{x} \# 2 \\
\text { SLAR }\end{array}$ & $\begin{array}{c}\mathrm{SiN}_{x} \# 2 \\
\text { SLAR, pass. }\end{array}$ & $\begin{array}{l}\mathrm{TiO}_{2} \\
\text { SLAR }\end{array}$ & $\begin{array}{c}\mathrm{TiO}_{2} \\
\text { SLAR, pass. }\end{array}$ & $\begin{array}{l}\mathrm{Si}_{3} \mathrm{~N}_{4} / \mathrm{TiO}_{2} \\
\text { DLAR }\end{array}$ & $\begin{array}{l}\mathrm{Si}_{3} \mathrm{~N}_{4} / \mathrm{TiO}_{2} \\
\text { DLAR, pass. }\end{array}$ \\
\hline \multirow[t]{2}{*}{ Opt. $d(\mathrm{~nm})$ full day } & $d_{1}$ & $75 \cdot 56$ & $53 \cdot 35$ & $62 \cdot 49$ & $37 \cdot 81$ & $51 \cdot 34$ & $18 \cdot 16$ \\
\hline & $d_{2}$ & - & - & - & - & $48 \cdot 61$ & $29 \cdot 81$ \\
\hline \multirow{2}{*}{ Opt. $d(\mathrm{~nm})$ AM1·5, norm. inc. } & $d_{1}$ & $73 \cdot 42$ & $50 \cdot 63$ & $61 \cdot 50$ & $36 \cdot 10$ & $48 \cdot 75$ & $15 \cdot 27$ \\
\hline & $d_{2}$ & - & - & - & - & $47 \cdot 51$ & $29 \cdot 33$ \\
\hline$J_{\text {scAve }}\left(\mathrm{mA} / \mathrm{cm}^{2}\right)$ full day & & $20 \cdot 47$ & $20 \cdot 19$ & $21 \cdot 34$ & $21 \cdot 10$ & $21 \cdot 55$ & $21 \cdot 11$ \\
\hline$J_{\text {scAve }}\left(\mathrm{mA} / \mathrm{cm}^{2}\right)$ AM1.5 norm. inc. & & $20 \cdot 47$ & $20 \cdot 18$ & $21 \cdot 34$ & $21 \cdot 09$ & $21 \cdot 54$ & $21 \cdot 11$ \\
\hline $\begin{array}{l}\% \text { increase in } J_{\text {scAve }} \text { using full day } \\
\text { optimization rather than AM1.5, norm. inc. }\end{array}$ & & $0 \cdot 017$ & $0 \cdot 034$ & 0.006 & $0 \cdot 030$ & $0 \cdot 007$ & $0 \cdot 037$ \\
\hline
\end{tabular}

$J_{\text {scAve }}$ is the predicted average short-circuit current produced in a coated cell over a whole day.

compared to an ideal ARC of approximately 5.6\%. This suggests that the benefits of employing a second layer are largely lost when a passivating layer is taken into consideration. This, in addition to the extra costs involved in depositing a second layer and potential compatibility problems of layer materials, means that SLARs are currently the dominant ARC technology for commercial cells.

\section{Sunrise to sunset vs. AM1 5 , normal incidence analysis}

Thicknesses of thin film coatings are usually optimized for PV applications by only considering the AM1.5 spectrum at normal incidence. Therefore, as a comparison, optimizations for AM1.5 at normal incidence have been performed and full day $J_{\text {scAve }}$ values for solar cells with these new film thicknesses have been calculated. The reference AM1.5 spectrum is taken from ASTM G173; the terrestrial global $37^{\circ}$ south-facing tilt values are used.

The results, given in Table VI, suggest that there is very little difference between the $J_{\mathrm{sc} \text { Ave }}$ achieved by the two methods, with the maximum difference of only $0.037 \%$ occurring with the passivated DLAR of $\mathrm{Si}_{3} \mathrm{~N}_{4} /$
$\mathrm{TiO}_{2}$. This is a consequence of the refraction of light at the glass surface, which narrows the angular range experienced by the underlying cell from $0-90^{\circ}$ to 0 $40^{\circ}$ as illustrated by Figure 3 . Reflectance changes little with AOI until light is incident at angles greater than $60-70^{\circ}$. Therefore, accounting for the full angular distribution of light is less important for encapsulated cells than it would be for non-encapsulated, laboratory type cells. In practice, fabrication tolerances and thickness uniformities are likely to be more significant than the small enhancements predicted for applying the full sunrise to sunset optimization procedure, and it can be concluded that optimizing using the AM1.5 spectrum at normal incidence is adequate for the case discussed.

\section{SOUTHAMPTON ROOF-MOUNTED CELL}

The above analysis considered the case in which an encapsulated cell was mounted horizontally at the equator so that it experiences the maximum PFD at the time of day when direct light is at normal incidence to 

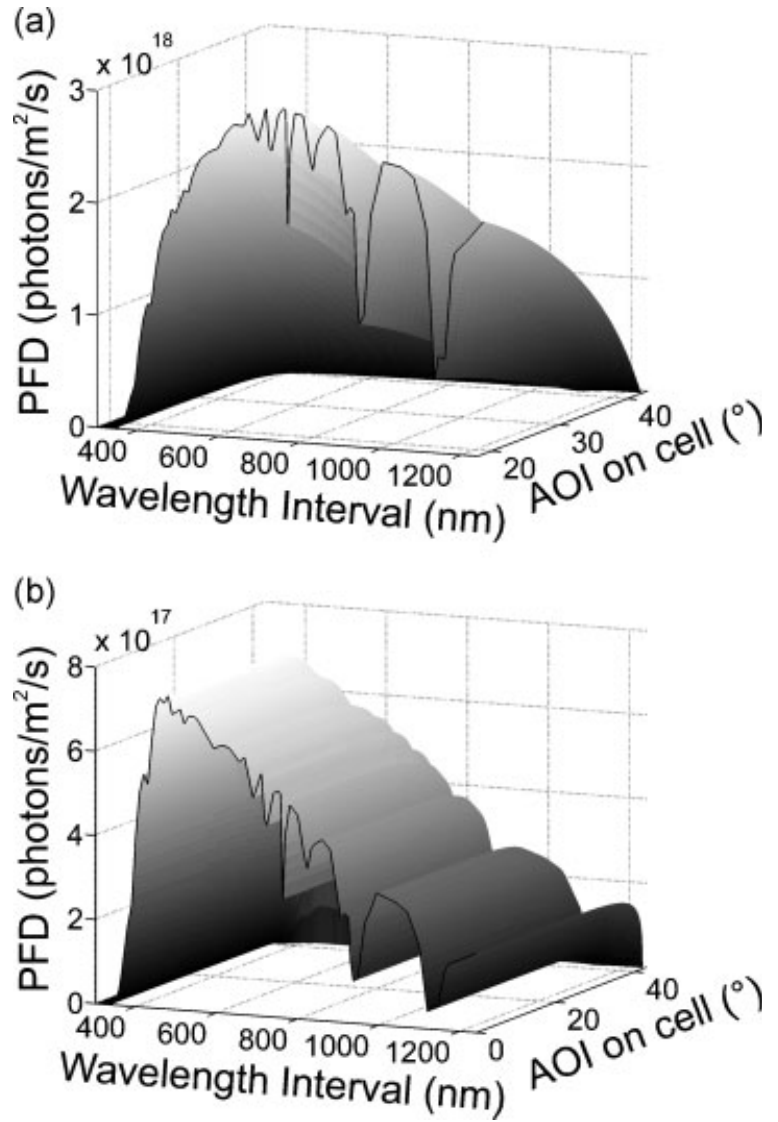

Figure 9. The wavelength and angular distribution of PFD experienced by a cell mounted on a sloped roof in Southampton: (a) direct light, (b) diffuse light. The wavelength interval is $1 \mathrm{~nm}$

the cell surface. In the real world, modules are positioned at other locations and in some cases, mounted at non-optimum angles, for example, on the sloped roof of a building. To demonstrate the versatility of the model, ARCs have been optimized for, as an example, an encapsulated cell mounted on a $5 / 12$ (22.6 $6^{\circ}$ from horizontal) sloped, south-facing rooftop in Southampton.

Spectra were obtained from SPCTRAL2, at 5-min intervals from dawn to peak irradiance, using the input values given for the Southampton cell in Table I. In this case, direct light is incident over a narrower range of angles, because the slope of the module, fixed by the slope of the roof, is no longer optimal for the position on earth. (As a rule of thumb, the optimum slope for year-round operation is equal to the latitude at which the module is sighted as this ensures that it is oriented so that when the sun is at its most intense, direct light is incident as close as possible to normal incidence. If only winter operation is considered, the optimum angle is latitude $+15^{\circ}$ and for summer operation, it is latitude $-15^{\circ} .^{37}$ ) Diffuse light can, however, be considered to be incident over all angles equally. Therefore, the contributions to the short-circuit current at each time of day of direct and diffuse parts of the incident spectra, which are plotted in Figure 9, are calculated separately. The two contributions are added before $J_{\text {scAve }}$ is calculated.

The model was used to optimize $\mathrm{SiN}_{x} \# 2$ and $\mathrm{TiO}_{2}$ SLARs, and a $\mathrm{Si}_{3} \mathrm{~N}_{4} / \mathrm{TiO}_{2}$ DLAR, with and without a $20 \mathrm{~nm}$ passivating oxide. The results (Table VII) reveal that the differences between the $J_{\text {scAve }}$ values for ARCs optimized using the full model compared to those optimized using AM1.5 at normal incidence are larger than those for the module situated at the equator. This arises from the change in the angular distribution of the light incident throughout a day on a cell situated on a sloped roof in Southampton compared to a cell orientated towards the sun. The angular distribution of direct light is not centered about normal incidence because of the new location and orientation of the cell. However, the largest difference, which is seen with the

Table VII. Comparison of full sunrise to sunset simulations with AM1·5, normal incidence simulations for the encapsulated cell mounted on a Southampton rooftop

\begin{tabular}{|c|c|c|c|c|c|c|c|}
\hline Coating & & $\begin{array}{c}\mathrm{SiN}_{x} \# 2 \\
\mathrm{SLAR}\end{array}$ & $\begin{array}{c}\operatorname{SiN}_{x} \# 2 \\
\text { SLAR, pass. }\end{array}$ & $\begin{array}{l}\mathrm{TiO}_{2} \\
\text { SLAR }\end{array}$ & $\begin{array}{c}\mathrm{TiO}_{2} \text { SLAR } \\
\text { pass. }\end{array}$ & $\begin{array}{c}\mathrm{Si}_{3} \mathrm{~N}_{4} / \mathrm{TiO}_{2} \\
\text { DLAR }\end{array}$ & $\begin{array}{l}\mathrm{Si}_{3} \mathrm{~N}_{4} / \mathrm{TiO}_{2} \\
\text { DLAR, pass. }\end{array}$ \\
\hline \multirow[t]{2}{*}{ Opt. $d(\mathrm{~nm})$ full day } & $d_{1}$ & 78.94 & $56 \cdot 79$ & $65 \cdot 11$ & $40 \cdot 28$ & $53 \cdot 43$ & 21.91 \\
\hline & $d_{2}$ & - & - & - & - & $50 \cdot 48$ & $31 \cdot 04$ \\
\hline \multirow{2}{*}{ Opt. $d(\mathrm{~nm}) \mathrm{AM} 1 \cdot 5$, norm. inc. } & $d_{1}$ & $73 \cdot 42$ & $50 \cdot 63$ & $61 \cdot 50$ & $36 \cdot 10$ & $48 \cdot 75$ & $15 \cdot 27$ \\
\hline & $d_{2}$ & - & - & - & - & $47 \cdot 51$ & $29 \cdot 33$ \\
\hline$J_{\text {scAve }}\left(\mathrm{mA} / \mathrm{cm}^{2}\right)$ full day & & $15 \cdot 42$ & $15 \cdot 23$ & $16 \cdot 06$ & $15 \cdot 89$ & $16 \cdot 21$ & $15 \cdot 91$ \\
\hline$J_{\text {scAve }}\left(\mathrm{mA} / \mathrm{cm}^{2}\right)$ AM1.5 norm. inc. & & $15 \cdot 40$ & $15 \cdot 20$ & $16 \cdot 04$ & $15 \cdot 87$ & $16 \cdot 21$ & $15 \cdot 88$ \\
\hline $\begin{array}{l}\% \text { increase in } J_{\text {scAve }} \text { using full day } \\
\text { optimization rather than AM1.5, norm. inc. }\end{array}$ & & $0 \cdot 108$ & $0 \cdot 159$ & $0 \cdot 075$ & $0 \cdot 167$ & $0 \cdot 040$ & $0 \cdot 184$ \\
\hline
\end{tabular}

$J_{\text {scAve }}$ is the predicted average short-circuit current produced in a coated cell over a whole day. 
passivated DLAR, is still only a $0.18 \%$ increase in $J_{\text {scAve }}$ for full day compared to AM1.5, normal incidence optimization. Again, such a small enhancement is likely to be insignificant in practice when fabrication tolerances and thickness and composition uniformities are taken into account.

\section{CONCLUSION}

We have presented a detailed approach to the material selection and optimization of the thicknesses of single and double-layer ARCs on an encapsulated, screenprinted silicon solar cell. This approach accounts for the spectral variations and changes of AOI that will be experienced by a typical fixed solar cell throughout a day. The method also takes into account absorption in the thin film coating and the spectral response of a cell.

The best-performing SLAR is made from $\mathrm{TiO}_{2}$ and is predicted to result in a $J_{\text {scAve }}$ only $4.6 \%$ lower than that of a cell with an ideal AR surface. This is further improved to only $3.5 \%$ of the ideal by a DLAR of RPECVD SiN $\# 1$ and $\mathrm{TiO}_{2}$. Decreases in performance of approximately $1 \%$ for SLARs and approximately $2 \%$ for DLARs are predicted when a passivating oxide is considered. When compared to coatings optimized using an AM1.5 spectrum at normal incidence, the model gives very little improvement for encapsulated cells. This is primarily because refraction at the glass interface narrows the angular range of incident light to $0-40^{\circ}$, and reflectance changes little with AOI until light is incident at angles greater than $60-70^{\circ}$. To demonstrate the use of the model for a module in a less symmetric setting, thin film ARCs were optimized for a module mounted on a sloped roof in Southampton. In this case, there is a $0.18 \%$ predicted increase in full day $J_{\text {scAve }}$ for full compared to AM1.5, normal incidence optimization of a passivated $\mathrm{Si}_{3} \mathrm{~N}_{4} / \mathrm{TiO}_{2}$ DLAR. However, we again consider this to be too small an enhancement to be of significance in a practical sense, when fabrication tolerances and thickness and composition uniformities are considered.

The model could be extended from a 1-day analysis to take into account annual spectral and angular distributions of incident light experienced by a cell at a specific location and orientation. This study has also only considered planar cells, but real cells and modules are often textured with features on the micron scale to further reduce reflectance. ${ }^{8,9}$ Incorporating ray-tracing techniques into the model would allow optimizations for textured cells to be performed by enabling the multiple reflections from the facets of the texture features to be considered. This analysis is also specific to silicon solar cells. The model could be extended to consider cells made from other materials for which different IQE and reflectance properties would result in different optimum thin film parameters.

Beyond SLARS, DLARS, and micron-scale texturing, we can envisage increasing use of novel antireflective and light-trapping techniques, specifically subwavelength-structured 'moth-eye' surfaces and other photonic or plasmonic schemes. ${ }^{10-15}$ As well as reducing reflectance to levels below those of even the best-performing thin film ARCS, these could allow increasingly asymmetric constructs that will lead to increased efficiency from sunrise to sunset. Such schemes are more likely to benefit from an optimization approach that considers the full range of spectral and angular variations in incident light.

\section{REFERENCES}

1. Zhao J, Green MA. Optimized antireflection coatings for high-efficiency silicon solar cells. IEEE Transactions on Electron Devices 1991; 38(8): 1925-1934.

2. Chiao SC, Zhou JL, Macleod HA. Optimized design of an antireflection coating for textured silicon solar-cells. Applied Optics 1993; 32(28): 5557-5560.

3. Bouhafs D, Moussi A, Chikouche A, Ruiz JM. Design and simulation of antireflection coating systems for optoelectronic devices: application to silicon solar cells. Solar Energy Materials and Solar Cells 1998; 52: 79-93.

4. Cid M, Stem N, Brunetti C, Beloto AF, Ramos CAS. Improvements in anti-reflection coatings for high-efficiency silicon solar cells. Surface an Coatings Technology 1998; 106(2-3): 117-120.

5. Nagel H, Aberle AG, Hezel R. Optimised antireflection coatings for planar silicon solar cells using remote PECVD silicon nitride and porous silicon dioxide. Progress in Photovoltaics: Research and Applications 1999; 7(4): 245-260.

6. Nubile P. Analytical design of antireflection coatings for silicon photovoltaic devices. Thin Solid Films 1999; 342(1-2): 257-261.

7. Richards BS, Rowlands SF, Honsberg CB, Cotter JE. $\mathrm{TiO}_{2}$ DLAR coatings for planar silicon solar cells. Progress in Photovoltaics: Research and Applications 2003; 11(1): 27-32.

8. Papet P, Nichiporuk O, Kaminski A, Rozier Y, Kraiem J, Lelievre JF, Chaumartin A, Fave A, Lemiti M. Pyramidal texturing of silicon solar cell with TMAH chemical anisotropic etching. Solar Energy Materials and Solar Cells 2006; 90(15): 2319-2328. 
9. Zhao J, Wang A, Green MA, Ferrazza F. $19.8 \%$ efficient "honeycomb" textured multicrystalline and $24.4 \%$ monocrystalline silicon solar cells. Applied Physics Letters 1998; 73(14): 1991-1993.

10. Clapham PB, Hutley MC. Reduction of lens reflexion by the "moth eye" principle. Nature 1973; 244(5414): 281282.

11. Wilson SJ, Hutley MC. The optical properties of moth eye antireflection surfaces. Optica Acta 1982; 29(7): 993-1009.

12. Sai H, Fujii H, Kanamori Y, Arafune K, Ohshita Y, Yugami H, Yamaguchi M. Numerical analysis and demonstration of submicron antireflective textures for crystalline silicon solar cells. Proceedings of the IEEE 4th World Conference on Photovoltaic Energy Conversion. Hawaii, 2006. pp. 1191-1194.

13. Toyota H, Takahara K, Okano M, Yotsuya T, Kikuta H. Fabrication of microcone array for antireflection structured surface using metal dotted pattern. Japanese Journal of Applied Physics Part 2: Letters 2001; 40(7B): L747-L749.

14. Boden SA, Bagnall DM. Bio-mimetic nanostructured surfaces for near-zero reflection sunrise to sunset. PVSAT-3. Durham, UK, 2007.

15. Boden SA, Bagnall DM. Tunable reflection minima of nanostructures antireflective surfaces. Applied Physics Letters 2008; 93: 133108.

16. Abeles F. Recherches sur la propagation des ondes electromagnetique sinusoidales dans les milieux stratifies. Applixation aux couches minces, Annals de Physique 1950(5): 596-640; 706-782.

17. Pedrotti FL, Pedrotti LM, Pedrotti LS. Introduction to Optics, 3rd ed. Pearson Prentice Hall: Upper Saddle River, New Jersey, 2007.

18. Green MA. High Efficiency Silicon Solar Cells. Trans Tech Publications Ltd.: Aedermannsdorf, 1987.

19. Conrady A. Applied Optics and Optical Design. Dover: New York, 1960.

20. Özer N. Optical properties and electrochromic characterization of sol-gel deposited ceria films. Solar Energy Materials and Solar Cells 2001; 68: 391-400.

21. Bruton T, Mason N, Roberts S, Nast Hartley O, Gledhill S, Fernandez J, Russell R, Warta W, Glunz S, Schultz O, Hermle M, Willeke G. Towards $20 \%$ efficient solar cells manufactured at 60MWp per annum. Proceedings of the Third World Conference on Photovoltaic Energy Conversion, 2003; 899-902.

22. Richards BS, Cotter JE, Honsberg CB, Wenham SR. Novel uses of $\mathrm{TiO}_{2}$ films in crystalline silicon solar cells. Proceedings of the 28th IEEE Photovoltaic Specialists Conference; 2000; 375-378.

23. Richards BS. Comparison of $\mathrm{TiO}_{2}$ and other dielectric coatings for buried-contact solar cells: a review. Progress in Photovoltaics: Research and Applications 2004; 12: 253-281.
24. Djurisic AB, Li EH. Modeling the index of refraction of insulating solids with a modified Lorentz oscillator model. Applied Optics 1998; 37(22): 5291-5297.

25. Richards BS. Single-material $\mathrm{TiO}_{2}$ double-layer antireflection coatings. Solar Energy Materials and Solar Cells 2003; 79: 369-390.

26. Khawaja EE, Durrani SMA, Al-Kuhaili MF. Determination of average refractive index of thin $\mathrm{CeO}_{2}$ films with large inhomogeneities. Journal of Physics D: Applied Physics 2003; 36: 545-551.

27. Bird RE, Riordan CJ. Simple solar spectral model for direct and diffuse irradiance on horizontal and tilted planes at the earth's surface for cloudless atmospheres. Journal of Climate and Applied Meteorology 1986; 25(1): 87-97.

28. El Amrani A, Mahrane A, Moussa FY, Boukennous Y. Solar module fabrication. International Journal of Photoenergy 2007: 27610.

29. Ebong A, Hilali M, Rohatgi A, Meier D, Ruby DS. Belt furnace gettering and passivation of $n$-web silicon for high-efficiency screen-printed front-surface-field solar cells. Progress in Photovoltaics: Research and Applications 2001; 9: 327-3332.

30. Lagarias JC, Reeds JA, Wright MH, Wright PE. Convergence properties of the Nelder-Mead simplex method in low dimensions. SIAM Journal of Optimization 1998; 9(1): 112-147.

31. Aberle AG. Surface passivation of crystalline silicon solar cells: a review. Progress in Photovoltaics: Research and Applications 2000; 8(5): 473-487.

32. Stephens AW, Aberle AG, Green MA. Surface recombination velocity measurements at the silicon-silicon dioxide interface by microwave-detected photoconductance decay. Journal of Applied Physics 1993; 76: 363-370.

33. Rohatgi A, Doshi P, Moschner J, Lauinger T, Aberle AG, Ruby DS. Comprehensive study of rapid, low cost silicon surface passivation technologies. IEEE Transactions on Electron Devices 2000; 47(5): 987-993.

34. Schmidt J, Lauinger T, Aberle AG, Hezel R. Record low surface recombination velocities on low-resistivity silicon solar cell substrates. Proceedings of the 25th IEEE Photovoltaic Specialist Conference, Washington, DC, 1996; 413-416.

35. Schmidt J, Kerr M, Cuevas A. Surface passivation of silicon solar cells using plasma-enhanced chemicalvapour-deposited $\mathrm{SiN}$ films and thin thermal $\mathrm{SiO} 2 /$ plasma SiN stacks. Semiconductor Science and Technology 2001; 16(3): 164-170.

36. Blakers AW, Zhao J, Wang A, Milne AM, Dai X, Green MA. $23 \%$ efficient silicon solar cell. Proceedings of the 9th European Communities Photovoltaic Science and Engineering Conference Kluwer: Freiburg, Germany, 1989; 328-329.

37. Fragaki A, Markvart T. Does climate change affect the design of stand-alone PV systems? Progress in Photovoltaics: Research and Applications 2005; 13: 635-639. 